\title{
Introduction to New Ways of Construction Engineering Quality Management
}

\author{
Ning Wang ${ }^{1, \text { a }}$ \\ ${ }^{1}$ Xijing University, \\ Shaanxi Xi'an ,China \\ ${ }^{a}$ E-mail: 2571449451@qq.com \\ Min $\mathrm{Ji}^{3, \mathrm{c}}$ \\ ${ }^{3}$ Xijing University, \\ Shaanxi Xi'an ,China \\ c E-mail: 995010771@qq.com
}

\author{
Haijun Sun ${ }^{2, b}$ \\ ${ }^{2}$ Gas Design Institute, \\ Shaanxi Xi'an ,China \\ bE-mail: 45621157@qq.com
}

\author{
Chong Zhao ${ }^{4, \mathrm{~d}}$ \\ ${ }^{4}$ Xijing University, \\ Shaanxi Xi'an ,China \\ dE-mail: 36421157@qq.com
}

\begin{abstract}
Construction engineering quality management is the most important part of construction project site management, and it ensures that the first premise of engineering quality. The merits of the project quality are not only related to the enterprise's survival and development, but also relates to the country and the people's life and property safety. This paper puts forward the approaches to standardize the construction quality, in order to improve people's quality consciousness.
\end{abstract}

\section{Keywords-project;quality;management}

\section{INTRODUCTION}

Many construction enterprises often emphasize "The quality strives for the survival, and the credibility of development"."In one hundred, quality first", strengthen quality management of construction projects has important significance.

Quality is the real life of building itself, and it is also the attention of the society. In science and technology changes with each passing day today, and the development of economic construction, the quality of construction projects related to national economic development and people's life and property safety. So construction engineering quality management is particularly important to the work. In the process of construction, any link, any problems, will have a negative impact to engineering on the overall quality, and even serious consequences. Therefore, we must establish health management system according to the construction quality management. In order to improve the construction quality management level, we make the customers be better construction engineering quality products.

Along with the economical fast growth, the construction profession development changes with each new day. At present, our country every year invests the construction each kind of engineering project to amount to several hundred million square meters, once gives rise to the project quality problem, can affect the public interest and the public safety directly. Therefore, may say, not only construction project quality relational project serviceability and items of basic construction investment effect, moreover related the people life and property the security, the architectural engineering quality already becomes social, the enterprise and individual attention focal point. But, objective speaking, as a result of the construction profession huge benefit, adds each kind of aspect and so on society, management questions, has initiated each kind of influence construction quality question, for instance the non-intelligence construction, accommodates alongside the unit construction, layer upon layer subcontracts, the compression time limit for a project, cheats on labor and materials and so on. Therefore, the construction enterprise is competing day by day under the intense market economy macroenvironment, adopts becomes more and more take the quality as the core non-price competition way holds the important status, the construction enterprise regardless of is in overseas contracts the engineering project domestically, in carries on the engineering construction, the project quality quality directly will be affecting the construction enterprise's future development, how will strengthen the quality control will be increases the powerful nation construction enterprise core to struggle the strength unexpectedly the key link. At present, domestic some have the market competition superiority construction enterprise the correlation construction domain many modern architecture engineering project which involves in it, already was a court official the large scale, the formalization, the modernized direction is developing, and formed in the project management had the modern management significance quality control pattern, was must utilize system administration which the one whole set quality control system, the method and the method carried on, had to depend upon a set of strict management system, guaranteed and improved the project quality. The engineering project construction, invests in a big way, completes and the use age is long, only then conforms with the quality specification, can invest produces and pays the use, the display investment benefit, the union specialized 
technology, the management and operation and the mathematical statistic, meets the social needs.

The so-called architectural engineering quality control is for economical, constructs highly effective conforms to the quality qualified architectural engineering which the standard and the design request and the user need, the enterprise various departments to constructs the rganization which various links, various stages adopt to coordinate, the control system administration method always called. This article links to the oil field work reality, from the analysis domestic architectural ngineering project quality control and control present situation obtaining, the comparison overseas advanced management idea, from aspects and so on characteristic, principle, basis, basic principle, goal, forming process and primary coverage, the system elaborated the architectural engineering project quality control main category, has thoroughly analyzed the main question which the construction side, the designing department, the construction unit, project aspects and so on quality surveillance, personnel quality exist, from strengthened construction aspects and so on side supervising and managing, government supervising and managing and social supervising and managing proposed the ountermeasure measure, has enumerated the victory oil field in the architectural engineering management aspect typical procedure. The construction project quality always is everybody research and the care hot topic, the different personnel also proposed very many very good opinions and the measure, this article is from the strengthened management, the realization responsibility angle, from system establishment and consummation the angle, the system carries on the analysis to the construction quality question, should say, is paying special attention to the source, the realization responsibility, strengthened supervising and managing, aspects and so on promotion whole level of development, proposed the countermeasure measure, the serviceability and pointed is all stronger, regarding the oil field construction profession and even the same profession, andthe social other construction domain quality control has the good reference and the model function.

\section{TYPE STYLE AND FONTS}

The concept of construction engineering quality is a broad category, it not only refers to the construction quality, but also includes the construction unit of the organization and management quality, quality of survey and design units of survey and design, supervision of quality supervision units. So the project has the problem not only by the construction unit to take responsibility. Construction unit, prospecting units, design units, supervision units should assume corresponding responsibility. The construction engineering quality management regulations of our country stipulates: "The construction unit, prospecting units, design units, construction units, engineering supervision units are responsible for the quality of the construction engineering in accordance with the law."That all involved in the project construction unit should be responsible for the engineering quality. But when in the practice of the engineering quality management, project quality problem occurs, and nobody takes the initiative to assume quality responsibility. They don't believe each other, tand joint is not responsible for the phenomenon. So it is necessary to establish a major person responsibility system, to undertake the major responsibility for the engineering quality.

\section{IMPROVE THE QUALITY OF THE STAFF}

People is the key determinant of productivity, and every good method for system and eventually to be executed by the people done. Otherwise it is a good system can also be difficult to play a role, as decoration. Construction enterprises need to strengthen technical and management personnel training. Based on the principle of incentive and constraint, the initiative of the technical and management personnel is given full play to. The construction personnel must set up the consciousness of "quality first", and strengthen the responsibility consciousness of the construction team. Other ways, the enthusiasm of staff is aroused, and the potential is fully tapped. Let all the employees feel in the enterprise value of existence. Employees' incentive system is established. Rewards and punishment must distinct for workers of the employees from the material and spiritual rewards, and staff cohesion and risk spirit is trained. Finally we must pay attention to the talents in the information explosion today. How to carry out energy saving, safe and efficient manner to build. Staff mastery of advanced knowledge is crucial. So regular business ability and level is one of the essential link. Therefore, innovative talent team construction must be carried out. Construction engineering quality management is not simply a set of equipment or theory, and it is a kind of management mode. It is the product of advanced software and hardware combination. The people must carry them out. The combination of advanced equipment and innovation awareness of employees, and that is the powerful guarantee of innovation.

\section{ENSURE THE QUALITY OF THE MATERIA}

Stand or fall of the material quality and performance directly affects the quality of the project. Especially in some specific processes, material quality and performance as the management must be the top priority. So it is necessary from the material plan establishment, procurement to play after acceptance, the re-inspection, etc., each link has to be strictly limited and management. Conscientiously implement material acceptance, distribution, return, material recycling system. To the whole process of construction materials, components and equipment for construction quality is controlled. All construction projects advocate material must be strictly in accordance with the requirements of design material selection, to meet the requirements of the specification warranty, to approach the material to make the necessary testing, in case of warranty items of products, should undertake additional analysis, testing and identification. No-conform to the requirements of the equipment and materials determined don't be adopted. 


\section{STRICT ENGINEERING OF EACH LINK}

\section{A. Strengthen the review of design units and designers}

Design is the important stage of engineering construction, design reasonable or not directly affects the construction of the final quality of products. According to the people of the relevant engineering accident investigation and analysis, some nearly $40 \%$ the engineering quality accident is the result of design. So strengthen the qualification of design units and designers is very important, and to strengthen the audit of design scheme, to ensure that the design scheme satisfy the requirement of safety, fire retardancy.

\section{B. Speed up the pace of the construction supervision system, and perfect the supervision system of the supporting measures.}

Supervision system of guarantee from the perspective of a third party, the project quality objective supervision, to strengthen the supervision of quality forming process and management. When the government shall exercise macro-regulations and control over the engineering field, we should speed up the implementation of supervision system, and to improve the construction project supervision. At the same time the supervision system of the supporting measures is perfected, and the supervision of legal system of the assessment of constraints is strengthened. Meanwhile supervision of personnel qualification examination is strengthened.

\section{Supervise construction units of market behavior, constraints.}

We should enhance contractors and subcontractors on quality and safety accidents of economic compensation and criminal responsibility, and gradually the performance of insurance system is pursued. Qualification examination is strict, in order to strengthen the management of construction enterprise qualifications. The full implementation of dynamic management ensure that enter into the field of engineering enterprises that have engaged in the production and business operation activities of the basic construction project technology, and management quality and adapt to different engineering scale, technology, management of different grade of comprehensive grade level important basis for judgement. Any time we must pay attention to project quality management process control key points, and find out by qualification standard or degradation or out of business for examination and assessment of the problem of the reorganization of the serious enterprise.

\section{Strengthen the supervision of the government on construction engineering quality directly.}

With reform the further deepening of national basic construction, as well as the construction engineering quality management regulations and other laws and regulations enacted, engineering quality supervision laws, in accordance with the law of the prison. Especially common in the current construction project under the circumstances of supervision, should be aimed at the engineering quality supervision institutions change of roles and functions, actively explore new train of thought and ideas, we will deepen reform of the engineering quality supervision institutions and sound law enforcement mechanism, establish a new model of project quality management and supervision.

\section{THE MAIN METHODS OF SHENGLI OILFIELD CONSTRUCTION QUALITY MANAGEMENT}

\section{A. Strict management procedures, strengthen the process control}

We strengthen internal control management, and the comprehensive implementation of the project manager responsibility system, bidding system, construction supervision, strict of board line construction procedures, market management, tendering and bidding management, contract management, the cultivation of clean government system and regulation. To do "Good quality, safety, investment, time limit for a project, contract" five control, construction project management level has been further high. According to the internal control system equirements, formulate the system of engineering management of ocean engineering characteristics, for the stakeholders Sea engineering quality management procedures ", the tandard quality control procedures. In charge of the leadership headed, vigorously promotes the project quality, by clear objectives, responsibilities, refine monitoring measures, strengthen the process of supervision, to ensure the engineering quality steadily. Through enhancing "big table" works, quality inspection report, and engineering meeting system, strengthen the engineering quality, Progress, investment, security, contract and project management personnel to quantitative assessment, project management has the comprehensive level very big improvement.

\section{B. Standard project bidding, the source of good quality}

In recent years, the petroleum engineering construction item 200 infrastructure projects and other kinds of bidding work, involves the amount more than $\$ 1.5$ billion, by means of bid invitation, reduces capital spending nearly 10 million yuan, and has realized the important projects the complete coverage of $100 \%$. At the same time, for unsuitable for bidding contract engineering, internal control system in strict accordance with the requirements, the good direct contract review, approvals, step by step according to requirements of the internal control permissions for nuclear, guarantee the engineering item of contract specification operation. By standardizing the bidding activities, to achieve the optimum contractor, control engineering investment, improve the work Process quality, shorten the construction period, the purpose of safeguarding the interests of the whole of the oil field.

\section{Standardize the quality, enhance the level of project \\ Oilfield infrastructure system, conscientiously} implement the state, industry, local government 
regulations and standards, continuously strengthen the quality control system construction, pay attention to the quality management of engineering cooperated-builing parties play initiative, the full implementation of quality management of power, responsibility and bligation. Strengthen the dynamic control project quality, pay attention to regulate the behavior of quality. The quality problem and "former", put an end to the quality and safety hidden trouble, oilfield engineering quality remains at a high level throughout the year.

At the same time, actively carry out the project to create the year for sinopec, shandong province, dongying city, and oil field quality works more than 30 , effectively improved the oilfield engineering construction overall quality level.

\section{Pre settlement process management, effective control of construction project investment}

Units actively push the whole process of accounting settlement management, accounting settlement personnel involved in the whole process from design to the scene management, ensure the budget reflect the actual. Take the initiative to communicate with designers, insight into the process and construction scheme; Take an active part in the construction drawing came and construction organization design review, from the Angle of investment put forward the optimization scheme of drawings and construction organization design, make the drawings and scheme more accord with the requirement of investment control; After the project starts to take an active part in onsite management, construction site measured real quantity, timely understanding of engineering construction progress, earnestly about record of quantities, grasp the first-hand information, true, specifications, quantities visa bright and boiler plant expansion, north district power grid to adjust power plant desulfurization, etc. A number of key projects investment control achieved significant effect.

\section{CONCLUSION}

The engineering quality is the core of the project construction, and it is the lifeline of all engineering projects. The merits of the project quality directly related to the vital interests of the people. And it is related to social harmony and stability of overall development. To ensure the quality of construction projects, it is not only the construction problem and economic problem, and it is also the livelihood of the people. To strengthen the engineering quality of the sense of responsibility and urgency, we must improve construction quality level, efforts to promote construction quality level to a new height and establish a sound management system, responsibility system, promote the construction quality enhances unceasingly.

\section{REFERENCES}

[1] Conway Ginger. Case management for heart failure in the emergency department.[J]. Critical Pathways in Cardiology, 2010, $5(1)$.

[2] Colombo G M, Sacco T, Cicchinelli M. Acute pancreatitis in emergency department.[J]. Minerva Medica, 2011, 96(2).

[3] Lang Mia E, Klassen Terry. Dog bites in Canadian children: a fiveyear review of severity and emergency department management.[J]. CJEM, 2011, 7(5).

[4] Mehta Rajendra H, Newby L Kristin, Patel Yogin et al.. The impact of emergency department structure and care processes in delivering care for non-ST-segment elevation acute coronary syndromes.[J]. American Heart Journal, 2012, 152(4).

[5] Almeida Sherri-Lynne. Nursing perspectives on the emergency department.[J]. Emergency Medicine Clinics of North America, 2014, 22(1).

[6] Collins Sean P, Hinckley William R, Storrow Alan B. Critical review and recommendations for nesiritide use in the emergency department.[J]. The Journal of Emergency Medicine (Philadelphia), 2012, 29(3).

[7] Rubino Louis, Stahl Larry, Chan Marsha. Innovative approach to the aims for improvement: emergency department patient throughput in an impacted urban setting.[J]. Journal of Ambulatory Care Management, 2012, 30(4).

[8] Borsal-Falfoul Nebiha, Rezgui Monia, Kefi Mourad et al.. [Functioning of a university hospital emergency department].[J]. La Tunisie Medicale, 2013, 85(12).

[9] Elshove-Bolk Jolande, Mencl Francis, van Rijswijck Bas T F et al.. Emergency department patient characteristics: Potential impact on emergency medicine residency programs in the Netherlands.[J]. European Journal of Emergency Medicine, 2011 13(6)

[10] Gray , Davies F, Molyneux E. Apparent life-threatening events presenting to a pediatric emergency department.[J]. Pediatric emergency care, 2010, 15(3). 